УДК 669:546.9/66.046.8

\title{
Precipitation of Platinum Group Metals \\ from Solutions of Precious Metals Refinery
}

\author{
Natalya V. Belousova ${ }^{a^{*}}$, \\ Oleg V. Belousov ${ }^{\mathrm{b}}$, Roman V. Borisov ${ }^{\mathrm{b}}$, \\ Aleksey M. Kolotushkin and Philipp A. Kylasov ${ }^{a}$ \\ ${ }^{a}$ Siberian Federal University \\ 79 Svobodny, Krasnoyarsk, 660041, Russia \\ ${ }^{b}$ Institute of Chemistry and Chemical Technology SB RAS \\ 50/24 Akademgorodok, Krasnoyarsk, 660036, Russia
}

Received 24.12.2015, received in revised form 12.01.2016, accepted 20.02.2016

Feasibility of precipitation of platinum group metals from solutions formed during the process of refining was considered in this work. It is of importance for reextracting valuable components and reduction of the volume of work-in-process. Particular attention has been given to the task of precipitation of iridium from waste solutions of precious metals refinery.

Keywords: platinum group metals, autoclave technologies, precipitation, solutions.

DOI: 10.17516/1998-2836-2016-9-1-6-12.

(C) Siberian Federal University. All rights reserved

* Corresponding author E-mail address: netnat1@rambler.ru 


\title{
Осаждение металлов платиновой группы
}

из растворов аффинажного производства

\author{
Н.В. Белоусова ${ }^{a}$ О.В. Белоусов ${ }^{\tilde{0}}$, \\ Р.В. Борисов ${ }^{\sigma}$, А.М. Колотушкин ${ }^{\text {, }}$ Ф.А. Кыласов ${ }^{a}$ \\ ${ }^{a}$ Сибирский федеральный университет \\ Россия, 660041, Красноярск, пр. Свободный, 79 \\ ${ }^{6}$ Институт химии и химической технологии СО РАН \\ Россия, 660036, Красноярск, Академгородок, 50/24
}

\begin{abstract}
В статье рассмотрена возможность осаждения металлов платиновой группы из растворов, образующихся в процессе аффинажа, в плане доизвлечения ценных компонентов и уменьшения объемов незавершенного производства. Особое внимание уделено задаче осаждения иридия из растворов финишной очистки.
\end{abstract}

Ключевые слова: металль платиновой группь, автоклавнье технологии, осаждение, pacmворы.

\section{Введение}

Одна из важнейших технологических задач в области гидрометаллургии платиновых металлов - повышение степени их извлечения при сокращении объемов незавершенного производства. Наиболее проблемными элементами с практической точки зрения являются иридий и родий. Процессы с участием их комплексных соединений отличаются кинетической инертностью, которая сказывается на показателях извлечения металлов из технологических растворов. Задача селективного количественного извлечения иридия и родия осложняется еще тем, что реальные системы многокомпонентные и их состав зависит от состава перерабатываемого сырья.

Один из возможных вариантов совершенствования технологий предполагает использование автоклавов, которые позволяют не только интенсифицировать процессы, но и решить одновременно ряд экологических и экономических вопросов. Весьма эффективны автоклавные технологии в металлургии цветных металлов [1-4].

В работах [3, 4] была показана возможность автоклавного обогащения типовых концентратов благородных металлов КП-1, КП-2 и КПП в сернокислых средах. При этом наряду с широко известными преимуществами использования автоклавных технологий было отмечено существенное улучшение процесса разделения фаз с ростом температуры. В то же время результаты показали, что в некоторых случаях суммарное содержание металлов платиновой группы (МПГ) в растворах автоклавной обработки достигало 10-25 мг/л. Сложившаяся ситуация предполагает поиск эффективных путей доизвлечения драгоценных металлов из растворов автоклавной обработки концентратов МПГ.

Еще более сложным объектом признаны растворы финишной очистки аффинажного производства, которые при высоком солевом фоне содержат всего 2 мг/л (в сумме) платиновых металлов. 
Цель данной работы - изучение процессов осаждения металлов платиновой группы (преимущественно родия и иридия) из растворов, полученных при автоклавном сернокислотном обогащении концентратов КП-1 и КПП, а также из растворов финишной очистки аффинажного производства.

\section{Методика экспериментов}

Для экспериментов использовали автоклавы, конструкция которых описана в работе [5], а также автоклав швейцарской фирмы Büchi AG, предназначенный для экспериментов с агрессивными средами и рассчитанный на работу до давлений 6 бар с максимальной температурой $180^{\circ} \mathrm{C}$.

Содержание элементов в растворах определяли стандартными методиками атомноабсорбционной спектрометрии на спектрофотометре марки A Analyst-400 (Perkin Elmer) c электротермическим атомизатором и масс-спектрометрией с индуктивно связанной плазмой (ИСП-МС) Agilent 7500a.

В качестве осадителей использовали гидразин солянокислый, формиат натрия, сульфит и тиосульфат натрия. Цементацию благородных металлов осуществляли с применением железного порошка.

В соответствии с объемом используемых автоклавов в реактор заливали исходный раствор $\left(30,50,250 \mathrm{~cm}^{3}\right)$; в чашечку, отделенную от раствора, добавляли необходимое количество осадителя; систему герметизировали и прогревали. После достижения необходимой температуры производили смешение фаз реагентов. Твердую фазу отделяли от раствора декантацией. Измерение ОВП осуществляли комбинированным электродом ЭСК-10601/7, прибор Анион 4100.

Модельные растворы иридия $(\mathrm{C}=50$ мг/л) готовили непосредственно перед экспериментом растворением в $1 \mathrm{M} \mathrm{HCl}$ навески гексахлороиридиата (III) калия, синтезированного по методике [6]. Контроль состава комплексного соединения проводили методами рентгенофазового и элементного анализов.

\section{Результаты и их обсуждение}

Для сравнения эффективности реагентов и выяснения, как влияет солевой фон на процессы осаждения платиновых металлов, первые эксперименты были выполнены с модельными растворами гексахлороиридиата (III) калия. Результаты показали, что при температурах 150 $180{ }^{\circ} \mathrm{C}$ в течение 1-2 ч происходит незначительное восстановление трехвалентного иридия солянокислым гидразином из солянокислых растворов; глубина осаждения составляла порядка $5-15 \%$.

Кардинально не поменяло ситуацию увеличение продолжительности времени восстановления до 4 ч. Можно предположить, что восстановление иридия солянокислым гидразином является сильно кинетически заторможенным процессом.

Аналогичная ситуация наблюдалась при использовании в качестве осадителя формиата натрия.

Применение тиосульфата натрия приводит к тому, что при температуре $130{ }^{\circ} \mathrm{C}$ уже через 30 мин иридий в растворе методом атомной абсорбции не регистрируется. Данные масс- 
спектрометрии показывают содержание иридия на уровне 0,05-0,07 мг/л, а увеличение температуры до $150{ }^{\circ} \mathrm{C}$ (30 мин) приводит к дальнейшему уменьшению концентрации иридия в растворе (до 0,01 мг/л), что свидетельствует о перспективности применения данного реагента.

В табл. 1, 2 отражены составы других объектов исследования - растворов, полученных при автоклавном сернокислотном обогащении концентратов КП-1 и КПП.

Из данных табл. 1 следует, что при сернокислотной обработке КП-1 из благородных металлов в раствор в значительной степени переходит лишь иридий (до 12 мг/л), тогда как в случае КПП в растворе обнаруживается родий, иридий, рутений, а также большое количество серебра.

Процедуру обезблагораживания этих растворов проводили в течение 30 мин как в открытых системах (температура $90{ }^{\circ} \mathrm{C}$ ), так и в автоклавных условиях (температура $180{ }^{\circ} \mathrm{C}$ ). В качестве осадителей использовали тиосульфат натрия и железный порошок.

Установлено, что из растворов, полученных при автоклавном сернокислотном обогащении КП-1, иридий осаждается до пределов обнаружения методом масс-спектрометрии с индуктивно связанной плазмой $(<0,1$ мкг/л) как в открытой, так и в закрытой системах, независимо от вида реагента.

Похожая картина наблюдалась и при осаждении МПГ из растворов сернокислотной автоклавной обработки КПП (табл. 3), за исключением того, что в открытой системе после использования тиосульфата натрия в растворе осталось небольшое количество родия $(0,5$ мг/л). Можно отметить, что в этих же условиях происходит наиболее полное осаждение серебра.

Исходный состав растворов финишной очистки аффинажного производства представлен в табл. 4.

Таблица 1. Состав растворов после сернокислотной автоклавной обработки концентрата КП-1 (мг/л)

\begin{tabular}{|c|c|c|c|c|c|c|}
\hline \multicolumn{7}{|c|}{ Благородные металлы } \\
\hline $\mathrm{Pt}$ & $\mathrm{Pd}$ & $\mathrm{Rh}$ & $\mathrm{Ir}$ & $\mathrm{Ru}$ & $\mathrm{Au}$ & $\mathrm{Ag}$ \\
\hline$<0,1$ & $<0,1$ & $<0,1$ & 11,5 & 0,1 & $<0,1$ & 0,15 \\
\hline \multicolumn{7}{|c|}{ Примесные цветные металлы } \\
\hline $\mathrm{Te}$ & $\mathrm{As}$ & $\mathrm{Cu}$ & $\mathrm{Fe}$ & $\mathrm{Ni}$ & $\mathrm{Pb}$ & $\mathrm{Se}$ \\
\hline$<0,1$ & $<0,1$ & 3850 & 900 & 1350 & 11,5 & - \\
\hline
\end{tabular}

Таблица 2. Состав растворов после сернокислотной автоклавной обработки платино-палладиевого концентрата (мг/л)

\begin{tabular}{|c|c|c|c|c|c|c|}
\hline \multicolumn{7}{|c|}{ Благородные металлы } \\
\hline $\mathrm{Pt}$ & $\mathrm{Pd}$ & $\mathrm{Rh}$ & $\mathrm{Ir}$ & $\mathrm{Ru}$ & $\mathrm{Au}$ & $\mathrm{Ag}$ \\
\hline$<0,1$ & $<0,1$ & 13,5 & 4 & 4,5 & $<0,1$ & 220 \\
\hline \multicolumn{7}{|c|}{ Примесные цветные металлы } \\
\hline $\mathrm{Te}$ & $\mathrm{As}$ & $\mathrm{Cu}$ & $\mathrm{Fe}$ & $\mathrm{Ni}$ & $\mathrm{Pb}$ & $\mathrm{Se}$ \\
\hline$<0,1$ & 750 & 1300 & 2000 & 2950 & 5,0 & - \\
\hline
\end{tabular}


В табл. 5 приведены данные по осаждению иридия из растворов финишной очистки тиосульфатом натрия, в табл. 6 - сульфитом натрия.

Анализ полученных результатов показывает, что в целом степень осаждения иридия выше при уменьшении ОВП. Сравнение тиосульфата и сульфита натрия в качестве осадителей иридия свидетельствует в пользу первого.

Таблица 3. Обезблагораживание растворов после автоклавной сернокислотной обработки концентрата КПП

\begin{tabular}{|c|c|c|c|}
\hline \multirow{2}{*}{$\begin{array}{c}\text { Определяемый } \\
\text { элемент }\end{array}$} & $180{ }^{\circ} \mathrm{C}$ (закрытая система) & \multicolumn{2}{|c|}{$90{ }^{\circ} \mathrm{C}$ (открытая система) } \\
\cline { 2 - 4 } & Тиосульфат натрия & Весстановитель & Тиосульфат натрия \\
\hline $\mathrm{Rh}$ & $<0,1$ & $<0,1$ & 0,5 \\
\hline $\mathrm{Ir}$ & $<0,1$ & $<0,1$ & $<0,1$ \\
\hline $\mathrm{Ru}$ & $<0,1$ & $<0,1$ & $<0,1$ \\
\hline $\mathrm{Ag}$ & 15 & 4,5 & 1,2 \\
\hline
\end{tabular}

Таблица 4. Состав солевых растворов финишной очистки аффинажного производства (мг/л)

\begin{tabular}{|c|c|c|c|c|c|c|c|c|c|c|c|}
\hline $\mathrm{Na}$ & $\mathrm{Fe}$ & $\mathrm{S}$ & $\mathrm{Mg}$ & $\mathrm{Cu}$ & $\mathrm{Cl}$ & $\mathrm{Ni}$ & $\mathrm{Zn}$ & $\mathrm{Se}$ & $\mathrm{Si}$ & $\mathrm{Ca}$ & $\mathrm{Mn}$ \\
\hline 6400 & 5900 & 860 & 670 & 100 & 51 & 47 & 46 & 41 & 26 & 26 & 17 \\
\hline $\mathrm{Al}$ & $\mathrm{K}$ & $\mathrm{Cd}$ & $\mathrm{Re}$ & $\mathrm{Co}$ & $\mathrm{As}$ & $\mathrm{Ag}$ & $\mathrm{Ir}$ & $\mathrm{Rh}$ & $\mathrm{Pt}$ & $\mathrm{Ru}$ & $\mathrm{Os}$ \\
\hline 13 & 13 & 13 & 4,5 & 1,6 & 0,63 & 2,1 & 1,6 & 0,6 & 0,11 & 0,1 & 0,078 \\
\hline
\end{tabular}

Таблица 5. Результаты экспериментов по осаждению иридия из растворов финишной очистки тиосульфатом натрия

\begin{tabular}{|c|c|c|c|c|}
\hline Температура, ${ }^{\circ} \mathrm{C}$ & Время, ч & $\begin{array}{c}\text { Количество } \\
\text { тиосульфата натрия, г/л }\end{array}$ & Е, мВ & $\begin{array}{c}\text { Степень } \\
\text { осаждения Ir, \% }\end{array}$ \\
\hline 110 & 1 & 12,4 & 266 & 77,8 \\
\hline 130 & 1 & 12,3 & 232 & 59,4 \\
\hline 130 & 1 & 25,9 & 102 & 76,7 \\
\hline 130 & 4 & 10,8 & 292 & 66,7 \\
\hline 130 & 8 & 10,8 & 236 & 66,7 \\
\hline 150 & 1 & 6,7 & 378 & 57,8 \\
\hline 150 & 4 & 10,0 & 413 & 50,0 \\
\hline 150 & 8 & 12,0 & 401 & 50,0 \\
\hline 150 & 4 & 25,4 & 385 & 50,0 \\
\hline 180 & 4 & 10,0 & 420 & 33,3 \\
\hline 180 & 8 & 10,0 & 429 & 33,3 \\
\hline
\end{tabular}


Таблица 6. Результаты экспериментов по осаждению иридия из растворов финишной очистки сульфитом натрия

\begin{tabular}{|c|c|c|c|c|}
\hline Температура, ${ }^{\circ} \mathrm{C}$ & Время, ч & $\begin{array}{c}\text { Количество } \\
\text { сульфита натрия, г/л }\end{array}$ & Е, мB & $\begin{array}{c}\text { Степень } \\
\text { осаждения Ir, \% }\end{array}$ \\
\hline 150 & 1 & 13,5 & 276 & 54,4 \\
\hline 150 & 1 & 55,8 & 113 & 62,8 \\
\hline 180 & 4 & 25,7 & 449 & 33,3 \\
\hline
\end{tabular}

Кроме того, был отмечен один неожиданный факт: увеличение температуры при прочих равных условиях неблагоприятно сказывается на осаждении родия и иридия, хотя имеющаяся на текущий момент информация по другим системам, содержащим металлы платиновой группы, говорит об обратном. Возможно, что это связано с высокой концентрацией железа в исходных растворах, которое в автоклавных условиях окисляется до $\mathrm{Fe}^{3+}$, причем этот процесс, как установлено ранее, при росте температуры проходит глубже. Образующееся трехвалентное железо вступает в конкурирующие реакции с серосодержащими восстановителями, тем самым влияя на процессы осаждения МПГ.

Для проверки сделанного предположения были проведены эксперименты, в которых сначала 2 ч гидролитически осаждали соединения железа при $150^{\circ} \mathrm{C}$, а затем, после отделения осадка, вводили тиосульфат натрия. При этом степень осаждения иридия составила 83,3 \% (при остаточной концентрации в растворе 0,3 мг/л), что превышает показатели, полученные в 4-часовых экспериментах при той же температуре без гидролиза. Необходимо заметить, что предварительные эксперименты по гидролитическому осаждению соединений железа показали, что металлы платиновой группы, присутствующие в растворах финишной очистки, на этих осадках не сорбируются [7].

\section{Заключение}

Представленные данные свидетельствуют о практически полном осаждении благородных металлов из растворов, получаемых в процессе аффинажа. Для увеличения степени осаждения иридия из растворов финишной очистки аффинажного производства с использованием автоклавных технологий необходимо предварительно выводить из системы железо.

\section{Список литературы}

1. King J.A., Knight D.A. Autoclave operations at Porgera. Hydrometallurgy 1992. V. 29 (1-3), P. 493-511.

2. Набойченко С.С., Шнеерсон Я. М., Калашникова М. И., Чугаев Л. В. Автоклавная гидрометаллургия цветных металлов. Т. 1-3, Екатеринбург: ГОУ ВПО УГТУ - УПИ. 2009. [Naboychenko S.S., Shneerson Y.M., Kalashnikova M.I., Chugaev L. V. Pressure hydrometallurgy of non - ferrous metals. Iss. 1 - 3, Ekaterinburg: Ural State Technical University - Ural Polytechnic Institute. 2009. (In Russ.)]

3. Belousov O.V., Belousova N.V., Ryumin A.I., Borisov R.V. Behavior of platinum - palladium concentrate under hydrothermal conditions. Russian Journal of Applied Chemistry 2015. V. 88 (1), P. 31-34. 
4. Belousov O.V., Belousova N.V., Ryumin A.I., Borisov R.V. Refining of platinum - palladium concentrate under hydrothermal. Russian Journal of Applied Chemistry 2015. V. 88 (6), P. 1075 1078 .

5. Belousov O.V., Belousova N.V., Sirotina A.V., Solovyov L.A., Zhyzhaev A.M., Mikhlin Yu.L. Formation of bimetallic $\mathrm{Au}-\mathrm{Pd}$ and $\mathrm{Au}-\mathrm{Pt}$ nanoparticles under hydrothermal conditions and microwave irradiation. Langmuir 2011. V. 27, P. 11697 - 11703.

6. Синтез комплексных соединений металлов платиновой группы: справочник/под ред. Черняева И.И. 1964. Л.: Наука. 340 c.[Sintez kompleksnykh soyedineniy metallov platinovoy gruppy: Spravochnik pod red . I.I. Chernyayeva. 1964. L .: Nauka. 340s . (In Russ.)]

7. Белоусова Н.В., Кыласов Ф.А., Гризан Н.В., Солохов Д.А. Поведение компонентов растворов финишной очистки аффинажного производства в автоклавных условиях. Journal of Siberian Federal University. Engineering \& Technologies. 2015. T. 4 (8), C. 514 - 518 [Belousova N.V., Kylasov Ph.A, Grizan N.V., Solokhov D.A. Behavoir of components of waste solutions of precious metals refinery in autoclave conditions. Journal of Siberian Federal University. Engineering \& Technologies 2015. V. 4 (8), P. 514 - 518. (In Russ.)]. 